\title{
Research Paper: Comparison of Postural Alignment of Osteopenic and Osteoporotic Women With Healthy Menopausal
}

\author{
Mahboubeh Eftekhari ${ }^{1}$ (D), Hassan Daneshmandi ${ }^{2}$ (D), Parisa Sedaghati2 ${ }^{*}$ (D) \\ 1. Department of Corrective Exercises and Sport Injuries, Faculty of Physical Education and Sports Sciences, University of Guilan, Rasht, Iran. \\ 2. Department of Sports Pathology and Corrective Movements, Faculty of Physical Education and Sports Sciences, University of Guilan, Rasht, Iran.
}

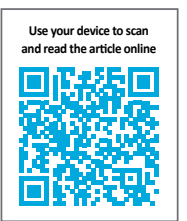

Chtation Eftekhari M, Daneshmandi H, Sedaghati P. Comparison of Postural Alignment of Osteopenic and Osteoporotic Women With Healthy Menopausal Women. Physical Treatments. 2021; 11(1):31-44. http://dx.doi.org/10.32598/ptj.11.1.434.1

: http://dx.doi.org/10.32598/ptj.11.1.434.1

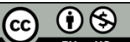

Article info:

Received: 16 Nov 2019

Accepted: 3 Oct b2020

Available Online: 01 Jan 2021

Keywords:

Osteoporosis, Osteopenia, Body alignment, Kyphosis

\begin{abstract}
A B S T R A C T
Purpose: Menopause in women causes problems, including osteoporosis due to hormonal changes. Besides, osteoporosis in postmenopausal women may be associated with musculoskeletal disorders followed by changes in the alignment of the body, especially the spine. Therefore, this study aimed to compare the posture of osteopenic, osteoporotic, and healthy menopausal women.

Methods: This was a cross-sectional study conducted on postmenopausal women (age range, 4565 years) referred to the Endocrinology and Rheumatology Clinic of Guilan University of Medical Sciences. Using the purposive sampling method, 90 people were selected as the study sample from this population and divided into three groups of 30 people: osteopenic, osteoporotic, and healthy. Then, the three groups were evaluated for body alignment (forward head, unequal shoulder, rounded shoulder, kyphosis, lordosis, and lower limb alignment). The obtained data were analyzed using ANOVA and the Scheffe Post Hoc test at the significance level of 0.05, in SPSS V. 22.

Results: The osteopenic and osteoporotic menopausal women significantly differed from the healthy menopause women in the following measures: forward head angle, curved neck angle, unequal shoulder ( $\mathrm{P}=0.003)$, kyphosis, lordosis, varus knee, flat foot $(\mathrm{P}=0.006)$, and pelvic tilt $(\mathrm{P}=0.001)$.

Conclusion: According to the results, the decrease in bone density at the osteopenic and osteoporotic levels can affect the postural alignment of the head, shoulders, and neck and the curvature of the spine in postmenopausal women in the three study groups. Therefore, more attention should be paid to the postural evaluation and screening of people prone to osteoporosis, to provide preventive training programs and exercises to improve their physical condition.
\end{abstract}

\section{* Corresponding Author:}

Parisa Sedaghati, PhD.

Address: Department of Sports Pathology and Corrective Movements, Faculty of Physical Education and Sports Sciences, University of Guilan, Rasht, Iran. Phone: +98 (912) 2768326

E-mail: sedaghati@guilan.ac.ir 


\section{Highlights}

- Postural alignment postmenopausal women in the three areas of the head, shoulders and neck and the curvature of the spine can be affected by a decrease in bone density in osteopenic and osteoprotic conditions.

- More attention is needed to the postural evaluation and screening of people at risk for osteoporosis.

\section{Plain Language Summary}

Osteoporosis in postmenopausal women may be associated with musculoskeletal disorders followed by changes in the alignment of the body, especially the spine. Therefore, this study aimed to compare the posture of osteopenic, osteoporotic, and healthy menopausal women. According to the results, the decrease in bone density at the osteopenic and osteoporotic levels can affect the postural alignment of the head, shoulders, and neck and the curvature of the spine in postmenopausal women in the three study groups.

\section{Introduction}

enopause is one of the natural stages in every woman's life and occurs M around the age of 48 to 65 years. This stage is associated with the cessation of ovulation and menstruation, the loss of fertility, and the symptoms of reduced and discontinued sex hormones, such as hot flashes, changes in body structure, osteoporosis, and changes in some organs of the body [1]. During this period, some familiar physiological and psychological changes occur in women [2]. One of the most important of these changes is musculoskeletal disorders, including osteoporosis, muscle atrophy, and the symptoms of muscle weakness; these changes are closely related to aging [3].

The female sex hormone estrogen plays a key role in maintaining the integrity of the musculoskeletal system. Therefore, a decrease in this hormone leads to muscle dysfunction [4]. Also, older people experience significantly more pain than others, because of the high prevalence of musculoskeletal disorders in this group. In different societies, more than $36 \%$ of the health care budget is spent on the elderly, also, most of these costs include pain control, especially musculoskeletal pain [5].

Osteoporosis is a skeletal disorder that disposes the person to increased fractures by damaging bone strength [6]. About $30 \%$ to $50 \%$ of women experience osteoporotic fractures during their lifetime [7]. Vertebral fractures as the most common fractures due to osteoporosis cause the kyphosis of the dorsal spine in people with osteoporosis; these fractures reduce the quality of life [8]. Also, women experience changes in the spine following osteoporosis, as they age. The most common postural changes are kyphosis that affects postural balance, gait, and postural function and oscillation [9].

The complications of kyphosis include increased pain, decreased muscle strength, decreased vertebral density, decreased height, decreased rib mobility, and even decreased respiratory function. Also, a curved posture can change movement strategies and upset the balance owing to bringing the center of gravity closer to the stability range [10]. On the other hand, the increase of the kyphosis angle reduces the range of motion of spinal extensions [11] and significantly affects physical performance, the ability to perform daily life activities, and ultimately, the quality of life [12].

Some studies indicate a decrease in muscle strength in the lumbar spine of women with osteoporosis. Moreover, this disorder is related to the decreased level of bone density in the lumbar spine. According to these studies, the exacerbation of erectile dysfunction may be related to the development of osteoporosis in these people [13-16]. Generally, disorders related to the postural curvature of the spine, including dorsal kyphosis and lumbar lordosis are simultaneously seen in patients with osteoporosis who have experienced a greater reduction in height and stature [17-19]. Osteoporosis in postmenopausal women may be associated with musculoskeletal disorders and are considered as risk factors for falls and fractures [7].

In a prospective study, Christian Roux et al. examined the status of thoracic kyphosis in postmenopausal women with osteoporosis. Also, T4 to T12 vertebral radiographs were used to measure the kyphosis. In the placebo group, patients with increased kyphosis experienced significantly more vertebral fractures than those with 
moderate kyphosis [20]. On the other hand, research shows that osteoporosis is significantly associated with sarcopenia [6-8], which is known as the age-related loss of muscle mass and skeletal function [21].

Limited studies considered osteoporosis and postural status, and if they did, they would be mainly from the perspective of the spine. Thus, this study considered spinal changes and the prevalence of hypokyphosis [16, 19, 20]; other postural disorders were less studied. Therefore, addressing the issue of menopause and its associated musculoskeletal consequences are very important from various individual and social aspects.

Studies in people with osteoporosis show a deviation from the proper posture, which negatively affects muscle function, causes muscle imbalance, and predisposes a person to musculoskeletal and neurological disorders. Besides, biomechanical changes due to abnormal orientation can affect the forces acting on the joints, the mechanical performance of the muscles, and the function of in-depth senses. Altering the center of gravity, these changes in body posture lead to the loss of body balance and increase the likelihood of falls and fractures [22]. So far, no study has examined or compared the postural alignment of osteopenic and osteoporotic women with healthy menopausal women, despite the importance of the subject and the limitations of studies on the effect of osteoporosis severity on postural status. Therefore, this study aimed to conduct a comparison.

\section{Materials and Methods}

The present research was a cross-sectional analytical study. The statistical population included all the elderly women aged 45 to 65 years who were referred to the Endocrinology and Rheumatology Clinic of Guilan University of Medical Sciences, in 2018. They had experienced at least two years of their menopause and were tested for bone density on the advice of a specialist. Besides, the statistical sample of the study included 90 women who were purposefully divided into three groups of 30 (osteoporotic group, osteopenic group, and healthy group), based on the inclusion and exclusion criteria.

The inclusion criteria for the present study were as follows: women in the age range of 45 to 65 years; having a history of at least two years of menopause; giving the bone density test; having a normal Body Mass Index (BMI); not participating in regular exercise for at least one year before the study; no history of fracture due to osteoporosis; no secondary osteoporosis; no prolonged immobility; no insulin-dependent diabetes; not consum- ing smoke, alcohol, or corticosteroids; no hearing-related diseases; no neuromuscular diseases; and no chronic orthopedics diseases (rheumatism and chondromalacia).

According to the $\mathrm{T}$ scores reported in BMI test, the study samples were assigned into three groups: osteoporotic or osteoporosis ( $\mathrm{T}$ score $\leq-2.5$ ), osteopenic or osteopenia $(-2.5<\mathrm{T}$ score $\leq-1)$, and healthy group (T score $>-1$ ) [1]. The samples of all three groups were matched in terms of demographic characteristics, including age, height, weight, and BMI. The exclusion criteria included having a history of the trunk or lower limb surgery, determined injuries to the lower and/or upper limbs (such as degenerative changes in the knee joint, spine, etc), and a BMI of more than the normal range.

\section{Forward head assessment}

The forward head posture was assessed using the head position assessment device with measuring craniovertebral angle. Initially, the subject was asked to stand in a normal position and perform neck flexion and extension movements three times to eliminate the abnormal contractions of the neck area. Then, the Seventh Cervical (C7) vertebra was identified and marked. We adjusted the height of the measuring device to the height of the subjects and placed it next to them. The short arm of the L-shaped index of the device was placed on the $\mathrm{C7}$ vertebra, then, the middle line of the other index of the device was adjusted on the tragus of the ear. The angle specified by the device is the forward head anomaly angle: the closer this angle is to zero, the more severe the anomaly. A total of three measurements were made and a 2-minute rest is given to the subject at the intervals of the measures $[23,24]$.

\section{Rounded shoulder assessment}

Rounded shoulder is a condition that anteriorly involves the movement of the shoulder joint in kyphosis. For this anomaly, a special measuring device is used to measure the rate of the movement of the shoulder joint forward. In this method, the subject was asked to stand back to the wall at a distance of $10 \mathrm{~cm}$ and in a normal position. Then, the measuring device was placed at a level above the subject's shoulder and leaned against the wall. At this time, the device must be parallel to the ground, based on the water level in the device. Then, the examiner moves the index arm of the device and places the posterior edge of the index in front of the acromion appendage. Hence, the rate of the shoulder joint forward is visible in centimeters. We performed the same process for the opposite shoulder. Finally, the average distance 

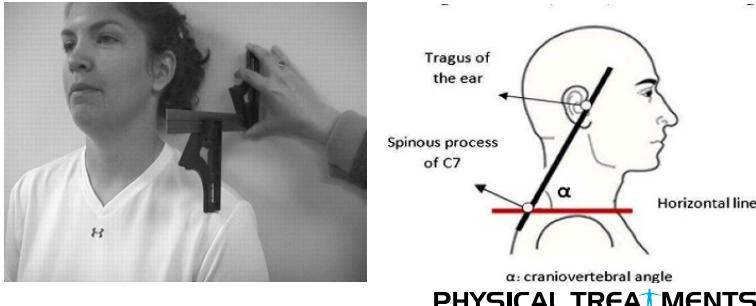

Figure 1. Measuring head forward (right) and rounded shoulder (left)

of the right and left shoulders from the wall minus $10 \mathrm{~cm}$ was considered as the last acromial appendage distance from the wall (Figure 1).

\section{Wryneck (torticollis) assessment}

A neck tilt assessment tool was used to measure the neck tilt. Achieve this, we recorded the angle of the soft interface between the two ears and the marked horizon line, from the front view. Also, using the same device, the angle between the two coracoid process and the marked horizon line was measured to assess the impaired shoulder [25].

\section{Assessment of lordosis and kyphosis}

A $60 \mathrm{~cm}$ flexible ruler (Kering brand) was used to measure the angle of lordosis kyphosis and the arches of the spine. This is a noninvasive and valid measurement method, compared with the X-ray method. The lumbar and dorsal curvatures were measured as follows: the subjects were asked to stand without upper body covering. Then, the examiner identified the spinal processes of T2, T12, L1, and S2 by touching them. Next, the subjects were asked to stand in a normal and comfortable position with bare feet and about a $15 \mathrm{~cm}$ distance between the legs. Also, the head was in a normal position and the subject was looking forward (Figure 2). The subjects were asked to keep the normal posture for about three minutes

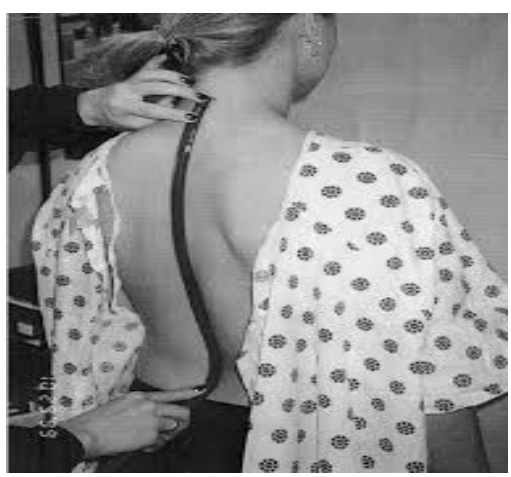

Figure 2. Measuring the angle of kyphosis and lordosis with a flexible ruler $\mathrm{T} 2$, T12, and L1 indicate spinal processes. while distributing the weight evenly on two legs until return to their normal state.

The flexible ruler was placed between the second and twelfth dorsal vertebrae, and then, on the first lumbar vertebra and the second sacral vertebra on the subject's spinal processes. So that, the ruler took the shape of the dorsal and lumbar spine arches. Then, carefully and without changing its state, the ruler was placed on a white paper and the arc shapes were drawn. We marked the spinal processes points of the second and twelfth dorsal vertebrae, the first lumbar, and the second sacral vertebrae on the paper; these points were already marked on the ruler. After, the points obtained from the second and twelfth dorsal vertebrae, the first lumbar vertebra, and the second sacral vertebra were connected with straight lines, also, a line was drawn perpendicular to the arc. The steps of measuring and calculating the angle of the dorsal and lumbar spine arches were repeated three times; the calculated mean was recorded as the rate of the dorsal and lumbar spine curvature angle for each subject. Then, the lordosis and kyphosis angles were calculated using the following formula: $\theta=4 \arctan (2 \mathrm{~h} / \mathrm{l})$

A device called the tilt gauge (tiltmeter) was used to measure the pelvic tilt. We asked the subjects to stand in a normal position to measure the lateral tilt of the pelvis. Then, by touch, we identified and marked the upper-anterior pelvic spine. Placing two arms of the tilt gauge on the marked points, the rate of lateral pelvic deviations can be determined based on the degree of inclination (Figure 3) [26, 27].

\section{$Q$ angle assessment}

To measure the Q angle, the angle between the quadriceps muscle line and the patellar tendon line or the angle between the femoral line and the starting line from the tibia and center of the patella should be measured [28]. The Q angles of the subjects were measured in a 


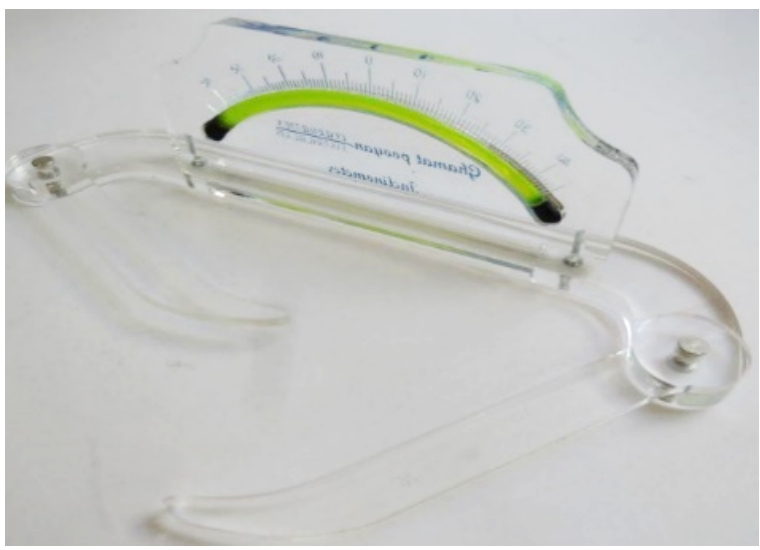

Figure 3. The pelvic tilt measuring device

standing position, where the knees and hips were fully extended without shoes. Before measuring the center of the patella, the examiner touched and marked the bulge of the tibia and the pelvic spine of the upper-anterior cruciate ligament. The center of the goniometer was placed on the center of the patella, its large arm in the alignment of the anterior-superior pelvic spine (the mechanical axis of the foot). Then, the angle was measured and recorded, when the quadriceps muscles were relaxed and free.

\section{Genu valgum assessment}

To measure the genu valgum and genu varum, the subjects comfortably stood with no shoes and socks in front of the examiner. Besides, their knees and thighs were visible, and they were not suffering from abnormal contraction and/or unusual tension in the thigh muscles. While the knees were close together, the distance between the inner ankles was measured with a caliper [29].

\section{Genu varum assessment}

To measure a varus knee (genu varum), the knees should be fully extended and the ankles placed fully near to each other. In this state, the distance between the two inner condyles (medial and lateral) of the thighs was measured and recorded by a caliper.

\section{Navicular drop assessment}

The navicular drop test was used to determine the rate of the foot pronation and measure the navicular drop. First, the subject sits on a chair, with the thighs and knees in a 90-degree flexion position, the soles of the feet on the ground, and the subtalar joint in a neutral position. Without bearing the weight, the examiner touched and marked the outcrop of the navicular drop and measured its distance to the ground with a ruler. Then, the subject
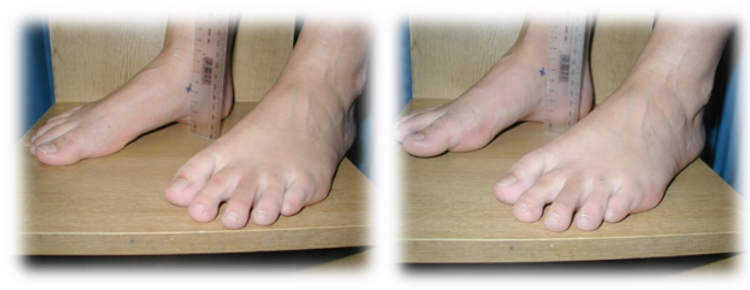

PHYSICAL TREA MENTS

Figure 4. Measuring the rate of navicular bone loss

was asked to stand and place the legs shoulder-width apart and the weight of the body evenly on both feet (weight-bearing). The distance of the navicular bone to the ground was measured again. The difference between the two conditions was recorded in millimeters as the rate of navicular bone drop (Figure 4) [30].

Moreover, in all measurements, the subjects stood, wore no shoes and socks, were perfectly comfortable in front of the examiner while their knees and thighs were visible, and suffered from no abnormal contraction and/ or unusual tension in the thigh muscles [31].

Descriptive and inferential statistical methods were used to analyze the research data. The Shapiro-Wilk test was used to determine the type of data distribution. Besides, the parametric one-way ANOVA was used to compare the means of the variables, because the data were normally distributed. Also, in the case of significant differences between the means of the variables, the Scheffe post hoc test was used to determine the differences. Data were analyzed using SPSS V. 22 at a significance level of 0.05 .

\section{Results}

Table 1 shows the Mean \pm SD of the demographic characteristics and research variables in the three groups of menopausal women: Osteopenic, osteoporotic, and healthy group. The results of comparing the three groups showed no significant difference in demographic characteristics.

Table 2 reports the results of the comparison of the body alignment variables. The three groups significantly differed in the rate of the head forward angle, neck tilt, rounded shoulder, kyphosis, lordosis, pelvic tilt, varus knee, $\mathrm{Q}$ angle, and flat foot $(\mathrm{P}=0.001)$. However, no significant difference was observed in the rate of rounded shoulder angle $(\mathrm{P}=0.14)$ and varus knee $(\mathrm{P}=0.39)$, between the three groups.

Table 3 shows the results of the Scheffe post hoc test. The rate of forward-head angle, kyphosis, lordosis, varus knee, and Q angle significantly differed between post- 
Table 1. Mean $\pm S D$ of the demographic characteristics of the study sample $(n=30)$

\begin{tabular}{|c|c|c|c|c|}
\hline \multirow{3}{*}{ Variables } & \multicolumn{3}{|c|}{ Mean $\pm S D$} & \multirow{3}{*}{$\mathbf{P}$} \\
\hline & \multicolumn{3}{|c|}{ Groups } & \\
\hline & Osteopenic & Osteoporotic & Healthy & \\
\hline Age (y) & $59.63 \pm 6.05$ & $60.53 \pm 6.38$ & $60.43 \pm 6.72$ & 0.84 \\
\hline Height (cm) & $156.5 \pm 4.78$ & $154.53 \pm 4.77$ & $155.63 \pm 5.67$ & 0.33 \\
\hline Weight (kg) & $68.60 \pm 10.18$ & $70.07 \pm 9.35$ & $71.70 \pm 8.8$ & 0.45 \\
\hline Menopausal age (y) & $47.73 \pm 4.8$ & $48.60 \pm 3.89$ & $49.63 \pm 3.97$ & 0.23 \\
\hline BMI $\left(\mathrm{kg} / \mathrm{m}^{2}\right)$ & $28.04 \pm 4.19$ & $29.37 \pm 3.93$ & $29.62 \pm 3.34$ & 0.24 \\
\hline
\end{tabular}

menopausal women (osteopenic-osteoporotic, osteopenic-healthy, and osteoporotic-healthy).

Also, the results of the post hoc test showed significant differences between osteoporotic and healthy postmenopausal women in the rate of tilted neck angle, rounded shoulder, and flat foot. There was also a significant difference between the rate of pelvic tilt angle in postmenopausal women (osteopenic-osteoporotic and osteoporotic-healthy).

\section{Discussion}

This study investigated the effect of osteoporosis with various severity on postmenopausal women. The results showed that postural alignment differed among the three groups of postmenopausal women with and without osteoporosis in the areas of the forward head, tilted neck, rounded shoulder, kyphosis, lordosis, pelvic tilt, varus knee, Q angle, and flat feet. Moreover, regarding dorsal kyphosis and lumbar lordosis, we observed a significant difference between all three groups with and without osteoporosis.

Some studies have shown similar results to the present study. For example, Miyakoshi et al. examined the postural alignment of people with and without osteoporosis, in various studies. These researchers showed increased chest kyphosis in patients with osteoporosis, compared with healthy people $[8,31,32]$. Their results also indicated an increase in lumbar lordosis in patients with osteoporosis, compared with healthy ones [32]. The proposed model of spinal deformity in their research shows that dorsal hyperkyphosis in the elderly with osteoporosis is exacerbated by the anterior displacement of the forward head and upper torso, because of the increased postural forces. In the cases with osteoporosis, the physiological kyphosis and increased stresses on the anterior edge of the vertebral body make the medial vertebrae of the spine more prominent [33].

Dorsal spinal hyperkyphosis and lumbar lordosis negatively impact on postural balance and result in destructed daily activities and quality of life [31, 34]. Besides, forward bending posture frequently occurs in the elderly, changes the center of gravity, and affects balance [34]. Research presented the mechanism of the simultaneous occurrence of dorsal kyphosis and lumbar lordosis: when dorsal kyphosis increases in the people with osteoporosis (as observed in the present study) their body compensates for the balance by increasing lumbar lordosis. Therefore, the bodies of the subjects in the osteoporosis group use the increase in lumbar lordosis as a means of compensating for thoracic hyperkyphosis [32].

Granito et al. compared the degree of dorsal kyphosis, the strength of the trunk muscles, and the sense of joint position among elderly women with and without osteoporosis. Their results showed that women with osteoporosis had significantly higher degrees of kyphosis and maximum lower torso extensor muscle torque. Besides, bone density was negatively associated with the degree of kyphosis. Also, the degree of kyphosis was negatively correlated with extensor muscle strength and joint position sense index. These researchers suggested the spinal fractures due to osteoporosis as one of the worst consequences of increased dorsal kyphosis in the elderly. However, the mechanisms associated with increased kyphosis in women with osteoporosis are completely unknown [35].

We can refer to the study of Muramoto et al. regarding the sensitivity of changes in the spine alignment. These authors recently reported that the changes of more than six degrees in the curvature of the spine can increase the 
Table 2. Results of the ANOVA test, comparing body alignment variables between the three study groups

\begin{tabular}{|c|c|c|c|c|c|c|c|}
\hline Variables & Mean $\pm S D^{a}$ & Test & Total Squares & df & Average Squares & $\mathbf{F}$ & $\mathbf{P}$ \\
\hline Head forward, osteopenic & $34.97 \pm 6.04$ & Intergroup & 1200.27 & 2 & 600.13 & \multirow{4}{*}{17.09} & \multirow{4}{*}{$0.001^{*}$} \\
\hline Head forward, osteoporotic & $30.90 \pm 5.6$ & & & & & & \\
\hline & & Intragroup & 3055.83 & 87 & 35.12 & & \\
\hline Head forward angle, healthy & $39.83 \pm 6.08$ & & & & & & \\
\hline Neck tilt, osteopenic & $177.63 \pm 1.56$ & Intergroup & 36.82 & 2 & 18.41 & \multirow{4}{*}{9.29} & \multirow{4}{*}{$0.001^{*}$} \\
\hline Neck tilt, osteoporotic & $176.04 \pm 1.4$ & & & & & & \\
\hline & & Intragroup & 172.33 & 87 & 1.98 & & \\
\hline Neck tilt, healthy & $178.40 \pm 1.24$ & & & & & & \\
\hline Rounded shoulder, osteopenic & $15.02 \pm 1.64$ & Intergroup & 21.22 & 2 & 10.61 & \multirow{4}{*}{2.04} & \multirow{4}{*}{0.14} \\
\hline Rounded shoulder angle, osteoporotic & $13.98 \pm 3.16$ & & & & & & \\
\hline & & Intragroup & 451.69 & 87 & 5.19 & & \\
\hline Rounded shoulder angle, healthy & $13.99 \pm 1.69$ & & & & & & \\
\hline Rounded shoulder angle, osteopenic & $178.63 \pm 1.18$ & Intergroup & 10.69 & 2 & 5.34 & \multirow{4}{*}{3.58} & \multirow{4}{*}{$0.03^{*}$} \\
\hline Uneven shoulder angle, osteoporotic & $178.00 \pm 1.29$ & & & & & & \\
\hline & & Intragroup & 129.77 & 87 & 1.5 & & \\
\hline Uneven shoulder angle, healthy & $178.8 \pm 1.19$ & & & & & & \\
\hline Kyphosis angle, osteopenic & $52.90 \pm 3.20$ & Intergroup & 1355.02 & 2 & 677.51 & \multirow{4}{*}{51.33} & \multirow{4}{*}{$0.001^{*}$} \\
\hline Kyphosis angle, osteoporotic & $58.37 \pm 2.8$ & & & & & & \\
\hline & & Intragroup & 1148.37 & 87 & 13020 & & \\
\hline Kyphosis angle, healthy & $48.90 \pm 4.61$ & & & & & & \\
\hline \multirow[t]{2}{*}{ Lordosis angle, osteopenic } & $42.77 \pm 3.12$ & & & & & \multirow{4}{*}{45.5} & \multirow{4}{*}{$0.001^{*}$} \\
\hline & & Intergroup & 1247.5 & 2 & 623.74 & & \\
\hline Lordosis angle, osteoporotic & $48.37 \pm 2.83$ & & & & & & \\
\hline Lordosis angle, healthy & $39.33 \pm 4.83$ & Intragroup & 1193 & 87 & 13.71 & & \\
\hline Pelvic tilt angle, osteopenic & $178.23 \pm 0.93$ & Intergroup & 36.69 & 2 & 17.48 & \multirow{4}{*}{13.82} & \multirow{4}{*}{$0.001^{*}$} \\
\hline Pelvic tilt angle, osteoporotic & $177.13 \pm 1.19$ & & & & & & \\
\hline & & Intragroup & 110.03 & & 1.26 & & \\
\hline Pelvic tilt angle, healthy & $178.60 \pm 1.22$ & & & 87 & & & \\
\hline Varus knee, osteopenic & $48.27 \pm 11.69$ & Intergroup & 9520.8 & 2 & 4760.4 & \multirow{4}{*}{27.22} & \multirow{4}{*}{$0.001^{*}$} \\
\hline \multirow[t]{2}{*}{ Varus knee, osteoporotic } & $58.07 \pm 13.31$ & & & & & & \\
\hline & & Intragroup & 15215.6 & 87 & 174.89 & & \\
\hline Varus knee, healthy & $33.06 \pm 14.51$ & & & & & & \\
\hline Varus knee, osteopenic & $13.13 \pm 19.04$ & Intergroup & 703.62 & 2 & 351.81 & \multirow{4}{*}{0.95} & \multirow{4}{*}{0.39} \\
\hline \multirow[t]{2}{*}{ Varus knee, osteoporotic } & $10.67 \pm 18.27$ & & & & & & \\
\hline & & Intragroup & 32119.5 & 87 & 369.19 & & \\
\hline Knee varus, healthy & $17.43 \pm 20.27$ & & & & & & \\
\hline \multirow[t]{2}{*}{ Q angle, osteopenic } & $16.70 \pm 1.26$ & & & & & \multirow{4}{*}{21.50} & \\
\hline & & Intergroup & 234.3 & 2 & 117.14 & & \\
\hline $\mathrm{Q}$ angle, osteoporotic & $20.63 \pm 3.11$ & & & & & & $0.001^{*}$ \\
\hline Q angle, healthy & $18.33 \pm 2.25$ & Intragroup & 473.93 & 87 & 5.45 & & \\
\hline Flat feet, osteopenic & $10 / 03 \pm 3.46$ & & & & & & \\
\hline & & Intergroup & 124.47 & 2 & 62.23 & & \\
\hline Flat feet, osteoporotic & $11.00 \pm 3.62$ & & & & & 5.5 & $0.006^{*}$ \\
\hline Flat feet, healthy & $8.16 \pm 3.02$ & Intragroup & 991.13 & 87 & 11.39 & & \\
\hline
\end{tabular}

aAll angles are in degrees, and the cruciate, knee braces, and the index of the flat foot are in mm; PHYSICAL TREA MENTS ${ }^{*} \mathrm{P}<0.05$. 
Table 3. Scheffe post hoc test results to compare body alignment angles in the postmenopausal women of osteopenic, osteoporotic, and healthy groups

\begin{tabular}{|c|c|c|c|c|}
\hline Variables & Groups & Means Difference ${ }^{a}$ & Means of Standard Error & $\mathbf{P}$ \\
\hline & Osteopenic-osteoporotic & 4.1 & 1.5 & $0.03^{*}$ \\
\hline \multirow[t]{3}{*}{ Head forward } & Osteopenic-healthy & -4.9 & 1.5 & $0.008^{*}$ \\
\hline & Osteoporotic-healthy & -8.9 & 1.5 & $0.001^{*}$ \\
\hline & Osteopenic-osteoporotic & 0.8 & 0.36 & 0.09 \\
\hline \multirow[t]{3}{*}{ Neck tilt } & Osteopenic-healthy & -0.77 & 0.36 & 0.11 \\
\hline & Osteoporotic-healthy & -1.57 & 0.36 & $0.001^{*}$ \\
\hline & Osteopenic-osteoporotic & 0.63 & 0.31 & 0.14 \\
\hline \multirow[t]{3}{*}{ Rounded shoulder } & Osteopenic-healthy & -0.17 & 0.31 & 0.87 \\
\hline & Osteoporotic-healthy & -0.8 & 0.31 & $0.04^{*}$ \\
\hline & Osteopenic-osteoporotic & -5.5 & 0.94 & $0.001^{*}$ \\
\hline \multirow[t]{3}{*}{ Kyphosis } & Osteopenic-healthy & 4 & 0.94 & $0.001^{*}$ \\
\hline & Osteoporotic-healthy & 9.5 & 0.94 & $0.001^{*}$ \\
\hline & Osteopenic-osteoporotic & -5.6 & 0.96 & $0.001^{*}$ \\
\hline \multirow[t]{3}{*}{ Lordosis } & Osteopenic-healthy & 3.4 & 0.96 & $0.002^{*}$ \\
\hline & Osteoporotic-healthy & 9.03 & 0.96 & $0.001^{*}$ \\
\hline & Osteopenic-osteoporotic & 1.1 & 0.29 & $0.001^{*}$ \\
\hline \multirow[t]{3}{*}{ Pelvic tilt } & Osteopenic-healthy & 00.4 & 0.29 & 0.45 \\
\hline & Osteoporotic-healthy & -1.5 & 0.29 & $0.001^{*}$ \\
\hline & Osteopenic-osteoporotic & -9.8 & 3.4 & $0.02^{*}$ \\
\hline \multirow[t]{3}{*}{ Crossed knee } & Osteopenic-healthy & 15.2 & 3.4 & $0.001^{*}$ \\
\hline & Osteoporotic-healthy & 25 & 3.4 & $0.001^{*}$ \\
\hline & Osteopenic-osteoporotic & -3.9 & 0.6 & $0.001^{*}$ \\
\hline \multirow[t]{3}{*}{ Q angle } & Osteopenic-healthy & -1.6 & 0.6 & $0.03^{*}$ \\
\hline & Osteoporotic- healthy & 2.3 & 0.6 & $0.01^{*}$ \\
\hline & Osteopenic-osteoporotic & -0.96 & 0.87 & 0.54 \\
\hline \multirow[t]{2}{*}{ Flat feet, $\mathrm{mm}$} & Osteopenic-healthy & 1.9 & 0.87 & 0.11 \\
\hline & Osteoporotic-healthy & 2.8 & 0.87 & $0.007^{*}$ \\
\hline
\end{tabular}

${ }^{a}$ All angles are in degrees, and the cruciate, knee braces, and the index of the flat foot are in $\mathrm{mm}$;

PHYSICAL TREA MENTS ${ }^{*} \mathrm{P}<0.05$. 
risk of locomotive syndrome, which requires nursing care services because of locomotion problems [36]. Postural instability as an effective factor in falling increases with age and the decrease of postural instability. The other factors affecting postural instability include changes in the curvature of the spine and hyperkyphosis and lordosis. The natural curvature of the thoracic and lumbar spine in the anterior-posterior plane often increases by age [37].

The prevalence of hyperkyphosis is reported to be between $20 \%$ to $40 \%$ in the elderly [38]. Postural kyphosis moves the body's center of gravity forward and out of the range of stability in the standing position. Therefore, the balance is reduced in these conditions, and the person is prone to fall, which is often accompanied by fractures [39]. In postmenopausal women, the weakness of the femoral opening muscles can increase lumbar lordosis, which increases the lumbar-sacral angle and pelvic tilt. Increased lumbar lordosis and low back pain and abdominal bulging are among the causes of this abnormality. Menopausal women, especially those with osteoporosis suffer from poor mobility and the weakness of muscles and ligaments that support the spine; this weakness causes lordosis abnormalities [40].

A review of previous studies shows the development of progressive musculoskeletal disorders followed by an increased risk of fractures after osteoporosis, in the elderly. Meanwhile, some studies have reported a high correlation between bone mineral density and body weight, especially in the spinal area, which plays a role in withstanding mechanical stresses. Some researchers believe that the mechanisms that explain this correlation are not well known. However, some researchers believe that the mechanical pressure on the bone tissue increases by weight gain and muscle weakness. Consequently, calcium uptake from the bone decreases and bone mineral density increases, causing a change in the normal position of the vertebrae and limbs.

In osteopenic and osteoporotic people, because of muscle weakness, inactivity, and calcium deficiency, more pressure is put on the skeletal structure and causes skeletal abnormalities [41]. Following osteoporosis, there is a possibility of vertebral fractures, which can lead to height reduction and kyphosis. Although vertebral fractures are painful, they often occur asymptomatically owing to osteoporosis. Also, the patients may only experience spinal abnormalities and progressive reduction in height. There is also a possibility of fracture in the lower part of the spine, because of the reduced endurance of the vertebrae. These fractures may even occur without any trauma. Spinal deformities may occur by the collapse or compression of the damaged vertebrae $[42,43]$.

Research shows that aging reduces bone density in the lumbar vertebrae and increases the prevalence of osteopenia. Researchers believe that low bone mineral density in osteopenic and osteoporotic individuals is probably caused by inactivity and reduced bone weight tolerance while walking. This interferes with the calcium absorption of the bones and decreases bone mineral density. These changes put too much pressure on the bones to maintain the body's stability, resulting in deformity in the long term [44].

In this study, the comparison of forward head angle in the three groups of osteoporosis and healthy subjects showed a significant difference. The angles were $30.90^{\circ}$ for the osteoporotic group, $34.97^{\circ}$ for the osteopenic group, and $39.83^{\circ}$ for the healthy group. One of the most common defective cervical spine postures is the forward head with a prevalence of $66 \%$. Some research suggests that this abnormality increases with age and is a key factor in intensifying respiratory problems [45]. The appearance of this defective posture increases the effect of gravitational forces on the head, the excessive extension of the head on the neck in the atlanto-occipital joint, the bending of the neck on the thorax, the withdrawal of the mandible, and the weakness of the deep flexor muscles of the neck.

On the other hand, the effect of gravity on the head increases by changing the position of the head forward. This effect leads to degenerative changes in the joints of the cervical spine and intervertebral disk damage, in the long run. Moreover, there are other local effects following the forward head, including increased pressure on blood vessels, decreased vertebral blood flow to the brain and brainstem, and decreased respiratory capacity [46].

Although this research focused on the comparison of abnormalities, such as kyphosis and lordosis in the elderly with and without osteoporosis, the results showed that the decrease in bone density in the osteopenic and osteoporotic elderly increased the forward head angle in the elderly, compared with healthy people.

Studies show that the rate of movement in the forward head and overload on the cervical vertebrae of people with a forward head are higher than those of healthy people. In other words, by increasing the head forward rate the overload increases, which can be one of the risk factors in people with osteoporosis and lead to instability, fractures, and neck pain in these people. For every 
inch of head forward movement, the pressure from the weight of the head will double. So that, for every inch the head moves forward, the muscles have to bear the double weight. Therefore, people with osteoporosis show more neck muscle weakness than others, considering the results of this study on the rate of the increase of the forward head angle in people with osteoporosis and osteopenia. Therefore, increased osteoporosis can aggravate neck pain and other injuries to the neck in the elderly, compared with other people with forward head posture $[47,48]$.

This study found a significant difference between the groups that were compared in neck tilt and rounded shoulder. The shoulder girdle area of the elderly is prone to injury, because of the lack of adequate joint support in this area and the high prevalence of muscle weakness [49]. Rounded shoulder complication is common in osteoporotic people. Also, it is more common in osteoporotic women owing to the less use of the upper limbs in physical activity and reduced physical activity. Because women are more active in fine motor hand activities with less strengthened large muscles in the upper body and upper limbs; this condition makes them prone to deformities in this area. On the other hand, one of the causes of the rounded shoulder is scoliosis, which can lead to shoulder sagging in the elderly, because of the prevalence of changes in the structure of the vertebrae [50].

Little research has been done on the prevalence of neck tilt disorders in the elderly, especially those with osteoporosis. However, Hasanvand et al. examined the structural profile of the elderly and showed a high prevalence of neck tilt [51]. In this regard, Vienna et al. stated the negative consequences of some diseases, such as osteoporosis and sensory and motor disorders [52].

The present results showed that the hearing loss in the elderly with osteoporosis was caused by the deficiencies of vestibular and atrial systems. Therefore, hearing loss can be a reason for the high rate of neck tilt [52]. Furthermore, neck tilt in such people can be attributed to premature fatigue. So that, people with osteoporosis suffer from muscle weakness due to low physical activity, which inevitably causes the head tilted to one side. Accordingly, the muscles of the opposite side are stretched and weakened. Hence, the sternocleidomastoid muscles are weakened on one side and short on the other side [53].

In the present study, all groups significantly differed in terms of pelvic lateral tilt, varus knee, $\mathrm{Q}$ angle, and flat foot. However, there was a significant difference in the flat foot variable only between the osteoporotic and healthy groups. Besides, the osteopenic and healthy groups did not significantly differ in pelvic tilt. Since osteopenic and osteoporosis in women mostly affect the hip, knee, and pelvic joints and reduce minerals and bone density, they can cause musculoskeletal disorders in these people. Thus, the knee angulation, Q angle increase, and pelvic tilt have a variety of causes, including physiological factors, congenital defects, metabolic bone diseases, adjacent joint injuries and fractures, etc. Since osteoporosis is a metabolic disease, it may be one of the causes of the high prevalence of cruciate ligament, increased $\mathrm{Q}$ angle, and pelvic tilt in these people.

\section{Conclusion}

Generally, limited and scattered studies have investigated the osteoporosis and its musculoskeletal effects in the elderly. These studies indicate, on one hand, the unfavorable nutritional status and the lack of energy, vitamin $\mathrm{D}$, protein, and micronutrients in this age group, and on the other hand, the prevalence of the related disease.

\section{Ethical Considerations}

\section{Compliance with ethical guidelines}

All ethical principles were considered in this article. The participants were completely informed about the research and its implementation stages; they were also assured about the confidentiality of their information; moreover, they were allowed to leave the study whenever they wish, and if desired, the results of the research would be available to them.

\section{Funding}

This article is extracted from a MA. thesis of the first authoe at the Department of Corrective Exercises and Sport Injuries, Faculty of Physical Education and Sports Sciences, University of Guilan, Rasht.

\section{Authors' contributions}

All authors participated in all stages of this research.

\section{Conflict of interest}

The authors declared no conflict of interest.

\section{Acknowledgments}

The authors would like to tank Medical Staff of the Endocrinology and Rheumatology Clinic of Guilan University of Medical Sciences. 


\section{References}

[1] Eslamian F, Shakouri SK, Hajalilu M, Toofan J, Kolahi S, Houshyar Y. [Effect of aerobic and strengthening exercises on balance, muscle strength and bone density in post menopausal women with primary osteopenia and osteoporosis (Persian)]. Studies in Medical Science. 2011; 22(3):166-75. http://umj.umsu.ac.ir/article-1-980-en.html

[2] Bachmann GA, Leiblum SR. The impact of hormones on menopausal sexuality: A literature review. Menopause. 2004; 11(1):120-30. [DOI:10.1097/01.GME.0000075502.60230.28] [PMID]

[3] Poehlman ET, Tchernof A. Traversing the menopause: Changes in energy expenditure and body composition. Coronary Artery Disease. 1998; 9(12):799-804. [DOI:10.1097/00019501-199809120-00004]

[4] Sipilä S, Poutamo J. Muscle performance, sex hormones and training in peri-menopausal and post-menopausal women. Scandinavian Journal of Medicine \& Science in Sports. 2003; 13(1):19-25. [DOI:10.1034/j.1600-0838.2003.20210.x] [PMID]

[5] Shamsi M, Safari A, Samadzadeh S, Yoosefpour N. The prevalence of musculoskeletal pain among above 50-yearold population referred to the Kermanshah-Iran health bus in 2016. BMC Research Notes. 2020; 13(1):72. [DOI:10.1186/ s13104-020-4940-6] [PMID] [PMCID]

[6] Cosman F, Krege JH, Looker AC, Schousboe JT, Fan B, Sarafrazi Isfahani S, et al. Spine fracture prevalence in a nationally representative sample of US women and men aged $\geq 40$ years: Results from the National Health and Nutrition Examination Survey (NHANES) 2013-2014. Osteoporosis International. 2017; 28(6):1857-66. [DOI:10.1007/s00198-0173948-9] [PMID] [PMCID]

[7] Randell A, Sambrook PN, Nguyen TV, Lapsley H, Jones G, Kelly PJ, et al. Direct clinical and welfare costs of osteoporotic fractures in elderly men and women. Osteoporosis International. 1995; 5(6):427-32. [DOI:10.1007/BF01626603] [PMID]

[8] Miyakoshi N, Hongo M, Maekawa S, Ishikawa Y, Shimada Y, Itoi E. Back extensor strength and lumbar spinal mobility are predictors of quality of life in patients with postmenopausal osteoporosis. Osteoporosis International. 2007; 18(10):1397-403. [DOI:10.1007/s00198-007-0383-3] [PMID]

[9] Cunha-Henriques S, Costa-Paiva L, Pinto-Neto AM, FonsechiCarvesan G, Nanni L, Morais SS. Postmenopausal women with osteoporosis and musculoskeletal status: A comparative crosssectional study. Journal of Clinical Medicine Research. 2011; 3(4):168-76. [DOI:10.4021/jocmr537w] [PMID] [PMCID]

[10] Harrison RA, Siminoski K, Vethanayagam D, Majumdar SR Osteoporosis-related kyphosis and impairments in pulmonary function: A systematic review. Journal of Bone and Mineral Research. 2007; 22(3):447-57. [DOI:10.1359/jbmr.061202] [PMID]

[11] Wang HJ, Giambini H, Zhang WJ, Ye GH, Zhao C, An KN, et al. A modified sagittal spine postural classification and its relationship to deformities and spinal mobility in a Chinese osteoporotic population. PLoS One. 2012; 7(6):e38560. [DOI:10.1371/ journal.pone.0038560] [PMID] [PMCID]

[12] Takahashi T, Ishida K, Hirose D, Nagano Y, Okumiya K, Nishinaga $\mathrm{M}$, et al. Trunk deformity is associated with a reduction in outdoor activities of daily living and life satisfaction in community-dwelling older people. Osteoporosis International. 2005; 16(3):273-9. [DOI:10.1007/s00198-004-1669-3] [PMID]
[13] Imagama S, Matsuyama Y, Hasegawa Y, Sakai Y, Ito Z, Ishiguro $\mathrm{N}$, et al. Back muscle strength and spinal mobility are predictors of quality of life in middle-aged and elderly males. European Spine Journal. 2011; 20(6):954-61. [DOI:10.1007/ s00586-010-1606-4] [PMID] [PMCID]

[14] Sinaki M, Wollan PC, Scott RW, Gelczer RK. Can strong back extensors prevent vertebral fractures in women with osteoporosis? Mayo Clinic Proceedings. 1996; 71(10):951-6. [DOI:10.1016/ S0025-6196(11)63768-3]

[15] Crepaldi G, Romanato G, Tonin P, Maggi S. Osteoporosis and body composition. Journal of Endocrinological Investigation. 2006; 30(Suppl 6):42-7. https://moh-it.pure.elsevier.com/en/ publications/osteoporosis-and-body-composition

[16] Mika A, Unnithan VB, Mika P. Differences in thoracic kyphosis and in back muscle strength in women with bone loss due to osteoporosis. Spine (Phila Pa 1976). 2005; 30(2):241-6. [DOI:10.1097/01.brs.0000150521.10071.df] [PMID]

[17] Sinaki M, Khosla S, Limburg PJ, Rogers JW, Murtaugh PA. Muscle strength in osteoporotic versus normal women. Osteoporosis International. 1993; 3(1):8-12. [DOI:10.1007/ BF01623170] [PMID]

[18] Ettinger B, Black DM, Palermo L, Nevitt MC, Melnikoff S, Cummings SR. Kyphosis in older women and its relation to back pain, disability and osteopenia: The study of osteoporotic fractures. Osteoporosis International. 1994; 4(1):55-60. [DOI:10.1007/BF02352262] [PMID]

[19] Cortet B, Houvenagel E, Puisieux F, Roches E, Garnier P, Delcambre B. Spinal curvatures and quality of life in women with vertebral fractures secondary to osteoporosis. Spine (Phila Pa 1976). 1999; 24(18):1921. [DOI:10.1097/00007632-19990915000010] [PMID]

[20] Roux C, Fechtenbaum J, Said-Nahal R, Kolta S, Briot K, Benhamou CL. Prospective assessment of thoracic kyphosis in postmenopausal women with osteoporosis. Journal of Bone and Mineral Research. 2010; 25(2):362-8. [DOI:10.1359/jbmr.090727] [PMID]

[21] Yoshimura N, Muraki S, Oka H, lidaka T, Kodama R, Kawaguchi $\mathrm{H}$, et al. Is osteoporosis a predictor for future sarcopenia or vice versa? Four-year observations between the second and third ROAD study surveys. Osteoporosis International. 2017; 28(1):189-99. [DOI:10.1007/s00198-016-3823-0] [PMID]

[22] Bell JS, Blacker N, Edwards S, Frank O, Alderman CP, Karan L, et al. Osteoporosis: Pharmacological prevention and management in older people. Australian Family Physician. 2012; 41(3):110-8. [PMID]

[23] Quek J, Pua YH, Clark RA, Bryant AL. Effects of thoracic kyphosis and forward head posture on cervical range of motion in older adults. Manual Therapy. 2013;18(1):65-71. [DOI:10.1016/j. math.2012.07.005] [PMID]

[24] Raine S, Twomey L. Posture of the head, shoulders and thoracic spine in comfortable erect standing. Australian Journal of Physiotherapy. 1994; 40(1):25-32. [DOI:10.1016/S00049514(14)60451-7]

[25] Asadi Ghalehney M, Norasteh AA, Daneshmandi H, Bahiraei S. [The comparison of head, shoulder, and spine in veteran soccer and volleyball players and non-athletes (Persian)]. The Scientific Journal of Rehabilitation Medicine. 2016; 5(2):173-83. http://medrehab.sbmu.ac.ir/article_1100186_en.html 
[26] Krahl H, Michaelis U, Pieper HG, Quack G, Montag M. Stimulation of bone growth through sports: A radiologic investigation of the upper extremities in professional tennis players. The American Journal of Sports Medicine. 1994; 22(6):751-7. [DOI:10 .1177/036354659402200605] [PMID]

[27] Young RS, Andrew PD, Cummings GS. Effect of simulating leg length inequality on pelvic torsion and trunk mobility. Gait \& Posture. 2000; 11(3):217-23. [DOI:10.1016/S09666362(00)00048-5]

[28] Herrington L. Does the change in $Q$ angle magnitude in unilateral stance differ when comparing asymptomatic individuals to those with patellofemoral pain? Physical Therapy in Sport. 2013; 14(2):94-7. [DOI:10.1016/j.ptsp.2012.02.008] [PMID]

[29] Ballal MS, Bruce CE, Nayagam S. Correcting genu varum and genu valgum in children by guided growth. Bone \& Joint Journal. 2010; 92(2):273-6. [DOI:10.1302/0301-620X.92B2.22937] [PMID]

[30] Schwellnus MP. Practical clinical lower limb biomechanical assessment in athletes. International SportMed Journal. 2001; 2(6):1-1. https://www.ingentaconnect.com/content/sabinet/ ismj/2001/00000002/00000006/art00001

[31] Miyakoshi N, Itoi E, Kobayashi M, Kodama H. Impact of postural deformities and spinal mobility on quality of life in postmenopausal osteoporosis. Osteoporosis International. 2003; 14(12):1007-12. [DOI:10.1007/s00198-003-1510-4] [PMID]

[32] Miyakoshi N, Kudo D, Hongo M, Kasukawa Y, Ishikawa Y, Shimada Y. Comparison of spinal alignment, muscular strength, and quality of life between women with postmenopausal osteoporosis and healthy volunteers. Osteoporosis International. 2017; 28(11):3153-60. [DOI:10.1007/s00198-017-4184-z] [PMID]

[33] Keller TS, Harrison DE, Colloca CJ, Harrison DD, Janik TJ. Prediction of osteoporotic spinal deformity. Spine (Phila Pa 1976). 2003; 28(5):455-62. [DOI:10.1097/01.BRS.0000048651.92777.30] [PMID]

[34] Ishikawa Y, Miyakoshi N, Kasukawa Y, Hongo M, Shimada Y. Spinal curvature and postural balance in patients with osteoporosis. Osteoporosis International. 2009; 20(12):2049-53. [DOI:10.1007/s00198-009-0919-9] [PMID]

[35] Granito RN, Aveiro MC, Renno ACM, Oishi J, Driusso P. Comparison of thoracic kyphosis degree, trunk muscle strength and joint position sense among healthy and osteoporotic elderly women: A cross-sectional preliminary study. Archives of Gerontology and Geriatrics. 2012; 54(2):e199-202. [DOI:10.1016/j. archger.2011.05.012] [PMID]

[36] Muramoto A, Imagama S, Ito Z, Hirano K, Ishiguro N, Hasegawa Y. Spinal sagittal balance substantially influences locomotive syndrome and physical performance in community-living middle-aged and elderly women. Journal of Orthopaedic Science. 2016; 21(2):216-21. [DOI:10.1016/j.jos.2015.12.016] [PMID]

[37] Vogt L, Hübscher M, Brettmann K, Banzer W, Fink M. Postural correction by osteoporosis orthosis (Osteo-med): A randomized, placebo-controlled trial. Prosthetics and Orthotics International. 2008; 32(1):103-10. [DOI:10.1080/03093640701838265] [PMID]

[38] Pfeifer M, Begerow B, Minne HW. Effects of a new spinal orthosis on posture, trunk strength, and quality of life in women with postmenopausal osteoporosis: A randomized trial. American Journal of Physical Medicine \& Rehabilitation. 2004; 83(3):17786. [DOI:10.1097/01.PHM.0000113403.16617.93] [PMID]
[39] Nouhi E, Mehdipour Rabari R, Abasszadeh A. [Effect of intensity and location of local musculoskeletal pain on quality of life in elderly, Kerman Iran (Persian)]. Hormozgan Medical Journal. 2012; 15(4):e88507. https://sites.kowsarpub. $\mathrm{com} / \mathrm{hmj} /$ articles/88507.html

[40] Yahia A, Ghroubi S, Mhiri C, Elleuch MH. Relationship between muscular strength, gait and postural parameters in multiple sclerosis. Annals of Physical and Rehabilitation Medicine. 2011; 54(3):144-55. [DOI:10.1016/j.rehab.2011.02.004] [PMID]

[41] Liu JM, Zhao HY, Ning G, Zhao YJ, Zhang LZ, Sun LH, et al. Relationship between body composition and bone mineral density in healthy young and premenopausal Chinese women. Osteoporosis International. 2004; 15(3):238-42. [DOI:10.1007/s00198-003-1536-7] [PMID]

[42] NIH Consensus Development Panel on Osteoporosis Prevention, Diagnosis, and Therapy. Osteoporosis prevention, diagnosis, and therapy. Journal of the American Medical Association (JAMA). 2001; 285(6):785-95. [DOI:10.1001/ jama.285.6.785] [PMID]

[43] Handa R, Kalla AA, Maalouf G. Osteoporosis in developing countries. Best Practice \& Research Clinical Rheumatology. 2008; 22(4):693-708. [DOI:10.1016/j.berh.2008.04.002] [PMID]

[44] Nucci P, Curiel B. Abnormal head posture due to ocular problems: A review. Current Pediatric Reviews. 2009; 5(2):105-11. [DOI:10.2174/157339609788185749]

[45] Horie J, Murata S, Inoue Y, Nakamura S, Maeda Y, Matsumoto $Y$, et al. A study of the influence of the pulmonary function on the angles of thoracic kyphosis and lumbar lordosis in community-dwelling elderly women. Journal of Physical Therapy Science. 2009; 21(2):169-72. [DOI:10.1589/ jpts.21.169]

[46] Rezvankhah Golsefidi N, Emami Hashemi SA. [Effect of four weeks of corrective exercises on forward head angle and spirometry parameters of female college students (Persian)]. Scientific Journal of Rehabilitation Medicine. 2016; 4(4):125-32. http://medrehab.sbmu.ac.ir/article_1100228.html

[47] Gauchard GC, Gangloff P, Jeandel C, Perrin PP. Physical activity improves gaze and posture control in the elderly. Neuroscience Research. 2003; 45(4):409-17. [DOI:10.1016/ S0168-0102(03)00008-7]

[48] Keyvanloo F, Seyyed Ahmadi M, Pejhan A. [Radiographic components in forward head posture and its relations whit gender and height (Persian)]. Journal of Sabzevar University of Medical Sciences. 2011; 17(4):266-73. http://jsums.medsab. ac.ir/article_45_8641aac63bfd5fe885f50efbdb4202eb.pdf

[49] Contreras Fernández JJ, Liendo Verdugo R, Osorio Feito M, Soza Rex F. Shoulder Pain in Swimmers, Pain in Perspective, Subhamay Ghosh, IntechOpen. Chapter. 2012; 6:119-46. Available from: https://www.intechopen.com/ books/pain-in-perspective/shoulder-pain-in-swimmers. [DOI:10.5772/51013].

[50] Mahmoodi Z, Sahebozamani M, Sharifian I, Sharifi H. [The effect of corrective exercises on the pain and degree of uneven shoulder deformity (Persian)]. Journal of Research in Sport Rehabilitation. 2014; 1(1):1-9. https://rsr.basu.ac.ir/ article_625.html?lang=en

[51] Hasanvand H, Bagheri Sabzevar A, Moradi H, Norasteh A. [Comparing the musculoskeletal profile of the elderly with 
and without history of falling (Persian)]. Salmand: Iranian Journal of Ageing. 2015; 10(3):72-81. http:// salmandj.uswr. ac.ir/article-1-690-en.html

[52] Manchaiah V, Baguley DM, Pyykkö I, Kentala E, Levo H. Positive experiences associated with acquired hearing loss, Ménière's disease, and tinnitus: A review. International Journal of Audiology. 2015; 54(1):1-10. [DOI:10.3109/14992 027.2014.953217] [PMID]

[53] Atula S, Sinkkonen ST, Saat R, Sairanen T, Atula T. Association of multiple sclerosis and sudden sensorineural hearing loss. Multiple Sclerosis Journal - Experimental, Translational and Clinical. 2016; 2:2055217316652155. [DOI:10.1177/2055217316652155] [PMID] [PMCID] 
